\title{
A Guide to Implementation of Time- Driven Activity -Based Costing in Saudi Electronic University
}

\author{
Salah Oraby ${ }^{1}$ \\ 1 Assistant Professor, Accounting Department, College of Administration and Finance, Saudi Electronic \\ University, Saudi Arabia \\ Correspondence: Salah Oraby, Assistant Professor, Accounting Department, College of Administration and \\ Finance, Saudi Electronic University, Saudi Arabia. E-mail: s.oraby@seu.edu.sa
}

Received: October 3, 2020

Accepted: November 10, 2020

Online Published: December 24, 2020

doi:10.5539/ijbm.v16n1p68

URL: https://doi.org/10.5539/ijbm.v16n1p68

\begin{abstract}
This research proposes a guide to implementation of time- driven activity -based costing (TDABC) in Saudi Electronic University (SEU) as an alternative to the traditional costing systems. It is worth mentioning that the cost accounting system should support mission and vision of the university by detecting any idle capacity and providing relevant information for rational decision-making as well as improving the quality of services provided to students and finally managing SEU's resources efficiently and effectively. According to Saudi's vision 2030, public universities in Saudi Arabia should act on both of revenue side and cost side.

In the current costing system of SEU, there are no cost pools at colleges' level, at academic departments' level, at courses' level, as well as at students' level. Rather cost pools found at university' level only. Therefore, the current costing system provides neither information on unit cost per student at any academic program nor information on the unused capacity at any resource centers.

Despite the fact that TDABC theoretically overcomes the criticism to both traditional costing system that uses direct labor or machine hours as a cost driver and the traditional activity- based costing (ABC that uses many transactions cost drivers to allocate overhead costs to cost objects. The implementation of TDABC is still challenging particularly in universities by using the time as the primary cost driver for allocating resource costs to final cost objects in academic programs especially the human labor is considered the main resource in universities.

The proposed guide to implementation TDABC provided SEU's management information, including but not limited to, the average actual unit cost per student in each academic program either per semester, or per year, comparing actual fees students paid in each academic program to the actual average unit cost in each academic program to determine whether SEU covers all costs. In addition, comparing the average unit cost per student among all academic programs and investigating reasons of variations. The guide helps management determine the unused capacity in each resource center as well as preparing budgets of all resource centers accurately based on the actual used capacity.
\end{abstract}

Keywords: activity based costing, time-driven activity -based costing- traditional costing system- resource center, Saudi electronic university

\section{Research Problem}

Today the accounting information system becomes an integral part of the management information system. Whereas, cost information generated by the accounting information system is being used by managers for planning, controlling and evaluating the operations. However, Under the SEU's current accounting system, past expenditures are allocated to common cost pools in general ledgers according to expenditure type such as salaries, maintenance, travel, etc. There is no accumulation of expenses by campus, division, section, academic programs, or activities to determine what is driving the cots.

(Lesetedi \& Mohee, 2019) pointed out that in public universities, budget is funded by government appropriations that historically estimated based on incremental models in absence of calculation of actual overhead costs for resource centers. Hence, deficit or excess funds may exist and students' tuition fees as sub source of the budget is estimated without taking into consideration the actual costs of programs. As a result, imbalance exists between 
sides of the demand and supply.

On the other hand, most of universities' costs are overhead costs (indirect costs) need to be allocated to both operating and supporting departments. Under traditional costing system, volume- based cost drivers are used to allocated indirect costs to cost object (students in each academic programs), but direct costs are traced directly to cost object without any problem under any costing system (Pierce \& Brown, 2006); Ismail, 2010).

Due to the dramatic changes in business environments, traditional costing system was replaced by the activitybased costing system to remove the existing shortcomings in the traditional costing system. $\mathrm{ABC}$ was developed in late 1980s to avoid cross subsidization between cost objects by using multiple transaction -based cost drivers (Cooper, 1987) (Cooper \& Kaplan, 1988).

In universities costs vary significantly due to the diversity of cost objects and using the traditional costing system in measuring cost objects generates imperfect information that will not be reliable for either strategic or operational decisions

(Paulo and Alex 2016). Currently cost management has been shifted dramatically from the traditional costing system that is mainly focuses on allocating overheads to cost objects to ABC system and to TDABC system.

However, academics and practitioners criticized $\mathrm{ABC}$ model as expensive and time consuming as well as arbitrary model. Whereas a vast majority of studies including Kaplan himself documented that ABC should be given up in the long term (Kaplan \& Anderson, 2004) (Byrne, et al., 2009). Therefore, TDABC has been found as an alternative to $\mathrm{ABC}$ to improve the allocation of overhead costs using time-based drivers. Under TDABC, cost pools in general ledger are assigned to resource centers and main activities are identified within each resource center that might be department, unit, sector, section within the organization that consumes human and non-human resources.

(Ratnatunga, et al., 2012) indicated that TDAB does not completely differentiate from $\mathrm{ABC}$ because the two models share the same cost pools for resource centers, and activities and cost objects. But the difference is fewer resource centers exist under TDABC and activity cost pools are found in the resource centers as well as cost drivers are time- based not transactions -based; as a result, the reduction of measurement errors.

Implementation of TDABC has been done since it was developed by (Kaplan \& Anderson, 2007) who indicated that TDABC was applied in more than 200 companies. However, the researcher found fewer case studies in the education industry for example (Yalianteta, et.al, 2018) (Pernot et.al, 2007) (Ratantingatal, et.al.2012) (Lesetedi\& Mahee, 2019) (Ringelstein, 2018). However, neither of them provided a comprehensive guide to implementation of TDABC at the university level, college level and academic programs level.

It has been proved that designing costing system in services industries is a hard process in general and in universities in particular because of the unique nature of services provided. Whereas services in universities are intangible and heterogonous as well as consumed just they produced (Lang field et al., 2009). Therefore, this study tries to fill in this gap in the literature.in addition, as far as the researcher knows, this study is the first in its kind in the kingdom.

\section{Research Objectives}

The purpose of this case study research is to propose a guide to help implement TDABC in SEU to manage its costs efficiently and effectively to achieve its mission and vision.

\section{Research Limitation}

Saudi Electronic University has 18 academic programs provided by four colleges in addition to the common first year. The proposed guide helps management implement TDABC at the university level in general and at the accounting program level at college of administration and finance. The guide shows the way and steps to calculate the unit cost per student in one academic program namely; accounting program that can be used for any academic program at any college in the university.

\section{Research Methodology}

The researcher uses the inductive approach in which the researcher starts with the related previous researches to develop the theory of the research topic and uses the deductive approach to explaining how to apply the theory to design SEU's updated costing system. The guide does not use inputs values either actual or estimated to calculate unit cost per student in each academic program to maintain SEU's data security. In addition, the focus of this research is to explain the way and steps of calculating rather than the results of calculations. 


\section{Literature Review and Theoretical Analysis}

Assigning direct costs to products, services and customers is an easy process in cost accounting but the opposite is correct regarding overhead costs whereas the researches have been continuing since decades ago to resolve the dilemma. In the literature review section, approaches to allocation overhead costs to cost objects are in-depth discussed and analyzed.

\subsection{Traditional Costing System}

Under traditional costing system, costs of both direct material and direct labor are traced economically and directly to final cost objects. However, manufacturing and non-manufacturing overheads have been allocated to the production by using the pre-determined overhead rate based on direct labor hours or volume of products as well as machine hours (Shabahan, 2012) (Gahramani, 2008) (Kowsari, 2013).

Traditional costing system gave inaccurate information about the product and services costs, which in turn misleading decision makers because it is direct costs- oriented by focusing on product costs such as direct labor, direct material, manufacturing overhead, while costs such as marketing, sale and administrative costs are allocated to income statement as period costs to comply with GAAP or IFRS.

\subsection{Activity Based Costing (ABC)}

Because of the shortcomings of traditional costing system, a new system called $\mathrm{ABC}$ came to existence and considered as one of the management accounting system innovation. It was developed in order to overcome the weaknesses of traditional costing systems by focusing on overhead costs to properly allocate them to cost objects.

ABC has been adopted widely in all industries including universities. However, (Broad \& Crowther, 2001) conducted a study on the appropriateness of $\mathrm{ABC}$ system in universities especially it has been adopted by universities in the United Kingdom claiming that the accurate determination of costs bring costs manageable. However, the study explained that the problem with $\mathrm{ABC}$ system in the university environment make the system inappropriate and the alternative to $\mathrm{ABC}$ is the throughput accounting.

On the other hand, (Hashmi, 2013) conducted a study to examine the differences in perceptions about the usefulness of costing information provided by $\mathrm{ABC}$ and the traditional costing system and between users and preparers. The results found that the information provided by $\mathrm{ABC}$ system is more useful than information provided by the traditional costing system. The results also founded no material difference between users and prepares regarding the quality of $\mathrm{ABC}$ system.

$\mathrm{ABC}$ is a new management accounting techniques developed by (Cooper \& Kaplan,1988) and used in both manufacturing and services sectors in response to dissatisfaction with traditional management accounting techniques that rely on volume-based methods for allocating overheads to cost objects (Ellis-Newman,2003)

The application of $\mathrm{ABC}$ system goes through two main phases. In the first phase, overhead costs are allocated to activities' cost pools using resource drivers. in the second phase, overhead costs are allocated from activities' cost pools to final cost objects using multiple transaction -based activity cost drivers, such as, number of machinery set up; customer orders; number of production times; number of purchasing orders, as well as and number of delivering products to customers (Weygandt et al., 2005).

(Berry, 1994) introduced a new method for overhead allocation in universities but he did not propose a methodology for ABC implementation. While (Goddard \& Ooi, 1998) explained that using ABC methodology in library services at the University of Southampton showed huge differences in the allocation of overheads costs in higher education institutions between both $\mathrm{ABC}$ method and the existing system. Authors argue that despite the $\mathrm{ABC}$ method might overcome some of the problems of overhead allocation. However, in practice, the $\mathrm{ABC}$ approach is still less efficient than in theory. In addition, it is very expensive to develop and maintain such a system.

(Cropper \& Cook, 2000) surveyed the current costing systems in the higher education sector, scanning recent published literature and analyzing the progress made by the academic institutions on the implementation of $\mathrm{ABC}$ system. The authors concluded that $\mathrm{ABC}$ is regarded as the most significant costing innovation in higher education, but findings suggest that the academic institutions have made a little bit progress so far towards implementing $\mathrm{ABC}$.

(Tatikonda \& Tatikonda, 2001) have studied the implementation of ABC in universities. They showed that simplifying the implementation resulted in several challenges. for examples; using single volume basis, summing fixed and variable costs in one cost pool, assuming all courses consume the same activities in the same ratios, 
when, in fact, some programs may subsidize others. However, the authors concluded that the $\mathrm{ABC}$ system might provide some advantages to academic institutions in the area of cost information, identification of resource needs, and distribution of scarce resources, course and program mix, cost control.

(Nidoo, 2011) Conducted a study to implement ABC in private universities in South Africa as a solution of the dissatisfaction of traditional costing system but he did not submit a comprehensive conceptual approach in this regard.

(Lutilsky \& Dragija, 2012) conducted a study on possibilities and challenges for implementation of ABC model as a complete costing method, at European universities. The study analyzed the major challenges in implementing. The study proposed guidelines for the development of a full costing system at the University of Zagreb using the pillars of $\mathrm{ABC}$ namely; classification of costs, activity centers, cost objects and activity cost drivers. Results indicates fewer universities implemented full costing systems because of many reasons, for example, resistance to change; inaccurate data provided by accounting systems; and universities are still income -oriented rather than cost- oriented.

(Charafa \& Rahmounib, 2014) examined the satisfaction of the adaptors of ABC for Moroccan companies using the Importance Performance Analysis (IPA) to identify strengths and weaknesses. Based on survey method, two samples of companies have been examined namely: $\mathrm{ABC}$ adaptors and non- $\mathrm{ABC}$ adaptors. The results pointed out that the $\mathrm{ABC}$ adopters were more efficient and satisfied with their costing system compared to non - $\mathrm{ABC}$ adaptors. However, they have not yet fully benefit from the advantages of the ABC system.

\subsection{Time -Driven Activity -Based Costing (TDABC)}

TDABC dates back to late 1990s by Steven Anderson and his Acron Company. He introduced this model under the name of Activity Based costing on Transactions. In 2001, Kaplan, the member of directors of Acron Company, contributed to developing this model and presented the theory of Time Driven Activity Based Costing. (Cooper \& Kaplan, 1988) supported the use of direct labor hours in service organizations as a cost driver. (Soltani \& Kalani, 2010) simplified the model by omitting both staff interview process and allocation resource costs to activities. The TDABC focus is on processes rather than activities and this makes the system more controllable. (Jurek \& Bars, 2012) pointed out TDABC model is simpler and less expensive; Implementation is quicker, easier, its operational is faster and less expensive than $\mathrm{ABC}$.

TDABC provides solutions to the shortcoming of both traditional costing and $\mathrm{ABC}$ systems. However, it has some inherent limitations. (Gervais et. al.2010) reported that there might be a confusion on whether to use standard costs or actual costs to set the unit cost per resource groups. in addition, the difficulties in measuring the required time to perform activities. TDABC explains any differences between the time needed by activities and the potential time departments' employees have and hence better capacity management (Barrett, 2005).

The implementation of TDABC revealed some advantages, such as; it is a system of easy design (Pernot et al., 2007). It allowed the study of efficacy and effectives of the operations from the available capacity and used capacity perspective (Barrett, 2005). It applies in industries and companies with complex cost objects (Kaplan \& Anderson 2004).On the other hand, some limitations have been observed, for examples, it requires much time and data to forecast time equations (Varila, Seppänen \& Suomala, 2007).

(Hooze \& Hansen, 2018) compared ABC and TDABC in terms of how to allocate resources to activities and finally to cost objects. The study showed that TDABC provides information that is more accurate than $\mathrm{ABC}$ when traceability of resources to activities is good even if activities' costs traceability to cost object is bad, while ABC provides information that is more accurate when activities' costs are traceable to products regards of the level of resource traceability to activities. The study examined the impact of mixing the two systems together. The study found that integration one $\mathrm{ABC}$ element with $\mathrm{TDABC}$ system improves accuracy, while integrating one TDABC element with ABC undermine accuracy.

(Rodriguez \& Nasiri, 2012) Explained that TDABC can estimate the quantity of idle resources and determine the different characteristics of the activities in the resource centers by estimating time equations in which the time consumed by an activity is a function of its different characteristics. Equations assign the time and the cost of the activity to the cost object based on characteristics of each cost object. (Kaplan \& Anderson, 2007) suggested estimating the time needed in minutes or hours to perform activities by direct observation, interviews and information by cost modelers.

Kowsari, (2013) pointed out some disadvantages of TDABC such as correct and reliable drivers are not available causing more problems rather than solving problems, such as, differences in time drivers, collecting and updating data. 
(Santans \& Afonso, 2014) investigated the applicability of TDABC by confining 20 studies published by different authors in ISI database covering different countries and different industries as well as different methodologies but unfortunately, none of those studies covered implementation in universities. (Ringelstein, 2018 ) conducted a study to investigate the claims whether TDABC is an alternative method to traditional ABC for accounting for overhead costs. The results pointed out that the differences between the two methods are minimal and problems of implementation remain unsolved.

(Lesetedi, \& Mohee, 2019) conducted a study to implement TDABC at BOU University. They developed a general and broad framework to apply the TDABC at the university level rather than college level.

Finally, the researcher can say that not all previous studies have developed a comprehensive and practical framework to implement TDABC in universities. Whereas no answers are given on many questions, for example, how are cost pools in general ledgers allocated to resource centers? What are resource centers at the university level? What are the main activities within resource centers? What are resource drivers? How is the practical capacity calculated in each resource center? What are the academic program in the university? What are the main activities within each academic program? How is the time required to perform the main activities calculated? How is cost per student in each academic program calculated? The researcher is trying to answer the questions in the case study.

\section{The Proposed Guide to Implementation of DTABC in SEU}

This section explains how to translate the pillars and the theory of TDABC into action in SEU's is costing system as it is the case study of this research.

\subsection{Saudi Electronic University Profile}

SEU is a government and educational institution established on $10 / 8 / 2011$ by a royal decree issued by king Abdullah bin Abdul-Aziz. SEU is the only specialized university in blended learning model offering graduate and undergraduate degree programs in the Kingdom of Saudi Arabia. SEU has now four colleges namely; college of administrative and financial sciences, College of Computer and Informatics, College of Health Sciences, College of Science and Theoretical Sciences.

\subsection{Assigning Cost Pools from SEU's Ledger Accounts to Recourse Centers' Cost Pools}

SEU's costing system does not accumulate costs by resource centers. Therefore, the first step is to assign cost data in general ledger to resource centers in separate cost pools that next allocated to the academic programs and finally allocated to the main activities of each academic program to calculate unit cost per student in each academic program based on the activities consumed by students. The research used traditional allocation bases to assign costs from general ledger accounts to cost centers whereas traceability is used for costs that can be traced to specific resource centers and allocation is used for common costs. (Table 1)

Table 1. Assigning cost pools from Seu' ledger accounts to recourse centers' cost pools

\begin{tabular}{ll}
\hline Cost Pools & Allocation Bases \\
\hline Salaries And Wages & Tracing \\
Rents & Square Meters \\
Insurance & Insures Assets Values \\
Depreciation Expense & Tracing / Assets Values \\
Supplies & Tracing/ No. Of Staff \\
Travel & Tracing \\
Graduation Expenses & Traced \\
Housing Allowances & Non Saudi Faculty Members \\
Freight \& Carrier & Allocated By Estimation \\
Printing \& Stationary & Allocated By Estimation \\
Telephone Expenses & Number Of Calls \\
Utility Expenses & Floor Space \\
\hline
\end{tabular}

Source: Prepared By the Researcher.

\subsection{Resource Centers}

In SEU there are two main types of resource centers the first is operating resource centers in which SEU's services are provided or processed to students and contribute directly to the profit; the second is supporting 
centers that consume resources and indirectly contribute to profitability. To determine resource centers in SEU, the organizational chart should be the starting points. Based on the organizational chart the following two supporting resource centers are proposed, the first is teaching- related resource centers the second is nonteaching- related resource centers. (Table 2). On the other hand, Operating resource centers are the Academic programs in all colleges of SEU plus common first year in which students consume different teaching activities and services. (Table 3)

Table 2. Supporting resource centers in Saudi electronic university and their cost drivers

\begin{tabular}{|c|c|}
\hline Resource Center & Resource Cost Driver \\
\hline University Rector. & No. of Students In Each Academic Program \\
\hline Vice Rector of Academic Affairs. & No. of Students In Each Academic Program \\
\hline Vice Rector of Branches. & No. of Students In Each Academic Program \\
\hline Vice Rector of Planning, Development And Quality. & No. of CRN in Each Academic Program \\
\hline Vice Rector For Graduate Studies And Research & No .Of Students In Each Graduate Program \\
\hline Vice Rector of Female Student Affairs. & No .Of Students In Each Female Academic Program \\
\hline Deanship of Admission And Student Affairs & No .Of Students In Each Academic Program \\
\hline Deanship of Graduate Studies & No .Of Students In Each Graduate Program \\
\hline Deanship of Scientific Research. & No .Of Students In Each Graduate Program \\
\hline Deanship of Information Technology & No. of CRN in Each Academic Program \\
\hline Institute For Research And Study & No .Of Students In Each Graduate Program \\
\hline Deanship of Human Resources. & $\begin{array}{l}\text { No. of Faculty Members and Staff In Each Academic } \\
\text { Program. }\end{array}$ \\
\hline Department of Knowledge Resources. & No. of Students In Each Academic Program. \\
\hline Department of Public Relation and Media. & No. of Students In Each Academic Program \\
\hline Department 0f Legal Affairs. & No. of Students In Each Academic Program \\
\hline Department of Scholarship And Recruitment. & No. of Students In Each Academic Program \\
\hline Department of Planning And Budget. & No. of Students In Each Academic Program \\
\hline Department of Internal Audit. & No. of Students In Each Academic Program \\
\hline Department of Administrative Affairs. & No. of Students In Each Academic Program \\
\hline Department of Finance. & No. of Students In Each Academic Program \\
\hline Department of Contracts And Purchase. & No. of Students In Each Academic Program \\
\hline Department of Safety And Security. & No. of Academic Programs \\
\hline Department of Student Support. & No. of Students In Each Academic Program \\
\hline Department of Storage And Warehouses. & No. of Academic Programs \\
\hline Department of Projects And Maintenance. & No. of Academic Programs \\
\hline Department of Correspondence. & No. of Academic Programs \\
\hline Department of Media Services. & No. of Academic Programs \\
\hline Department of Partnerships and Cooperation. & No. of Academic Programs \\
\hline
\end{tabular}

Source: Prepared by the Researcher.

Table 3. Operating resource centers in Saudi electronic university and their cost drivers

\begin{tabular}{lll}
\hline College & Resource Centers(Academic Programs) \\
\hline & Accounting \\
College of Administration and & Management \\
Finance & & E Commerce \\
& Finance \\
& MBA \\
& Information Technology \\
College of Computing $\quad$ And & Computer Science \\
Informatics & Data Science \\
& Master Of Science In Information Security \\
& Master In Cyber Security \\
College of Health Sciences & Health Informatics \\
& Public Health \\
& Master Of Healthcare Administration \\
College of Science & Arabic For Non-Speakers \\
Theoretical Studies & Andanities \\
& Basic Studies \\
First common year & English And Translation \\
\hline
\end{tabular}

Source: Prepared By the Researcher. 


\subsection{Calculating Unit Cost per Student in Academic Programs Offered by the College of Administration and} Finance

In this section, the study explains steps to calculate the cost per student in academic programs offered by the College of Administration and Finance in general and in accounting program in particular as an example as follows:

\subsubsection{Calculating Total Costs of Operating Resource Centers}

As mentioned earlier that operating resource centers or profit centers are the academic programs in College of Administration and Finance. Namely, four scientific bachelor degree program and one MBA business program. (Table 4).

As explained in (Table 4) the cost of each study program has both direct costs and overhead costs. While direct costs incurred within study programs, overhead costs are incurred within support departments either at the college level or at the university level. Under TDABC, overhead costs are assigned from support departments to study programs using resources drivers that causes the study program to consume costs from support departments as explained in (Table 2)

Table 4. Total cost of academic programs at the college of administration and finance

\begin{tabular}{llll}
\hline Study program & Direct cost & Overhead costs & Total costs \\
\hline Accounting & $\checkmark$ & $\checkmark$ & $\checkmark$ \\
Management & $\checkmark$ & $\checkmark$ & $\checkmark$ \\
E commerce & $\checkmark$ & $\checkmark$ & $\checkmark$ \\
Finance & $\checkmark$ & $\checkmark$ & $\checkmark$ \\
MBA & $\checkmark$ & $\checkmark$ & $\checkmark$ \\
Total & $\checkmark$ & $\checkmark$ & $\checkmark$ \\
\hline
\end{tabular}

Source: Prepared by the Researcher.

\subsubsection{Calculating the Practical Capacity}

As suggested by (Kaplan \& Anderson, 2004) the practical capacity could be estimated as a percentage of the theoretical capacity allowing deducting $20 \%$ of the theoretical capacity for having tea, breaks, pray, lunch, departure and arrival. Another alternative suggested by (Kaplan \& Anderson, 2004) to estimate the practical capacity by conducting reviews of past events and activities levels.

(Table 5) indicates that the Practical capacity is measured using a unit time and is expressed as percentages of the theoretical capacity after excluding the annual leave and the public holidays and the weekends, meeting, as well as training hours. Therefore, it is supposed that the total practical capacity of each study program is $80 \%$ of the total normal capacity of the faculty members' workload in each study program as explained by the following equation:

$\mathrm{Pc}=(\mathrm{w}-(\mathrm{a}+\mathrm{h} .+\mathrm{e})$ where: $\mathrm{pc}$ stands for the practical capacity for one faculty member, $\mathrm{w}$, stands for calendar weeks per years, a, stands for annual leave, h, stands for public holidays, e, stands for weekends. Hence, the normal capacity of working hours is 40 hours per week; the practical capacity of each faculty member will be 32 hours per week ( $80 \%$ x 40 hours).

Using the equation, the total practical capacity for each faculty member equals 32 hours*4 weeks * 10 months (a two month annual vacation has been excluded) $* 60$ minutes $=76,800$ minutes per year, or 38,400 per semester. The practical capacity per study program per year is calculated using the following equation:

$\mathrm{P}=\mathrm{pc}^{*} \mathrm{n}$ where, $\mathrm{p}$, stands for the practical capacity per program, $\mathrm{pc}$, stands for the practical capacity per faculty, $\mathrm{n}$, stands for number of faculty members.

$p=76,800^{*}$ No. of faculty members in study program. 
Table 5. The practical capacity of academic programs at the college of administration and finance

\begin{tabular}{lc}
\hline Study program & Practical Capacity In Minutes \\
\hline Accounting & $\checkmark$ \\
Management & $\checkmark$ \\
E commerce & $\checkmark$ \\
Finance & $\checkmark$ \\
MBA & $\checkmark$ \\
Total & $\checkmark$ \\
\hline
\end{tabular}

Source: Prepared By the Researcher.

\subsubsection{Calculating the Practical Capacity Rate of Academic Programs in College of Administration and Finance}

Now both of total cost and the practical capacity of each academic program are available (in Table 4 and 5). Therefore, the practical capacity rate of each Academic Programs is calculated by the following equation:

Unit cost capacity rate $=$ total costs of capacity supplied/ estimated practical capacity supplied.

$\mathrm{Cr}=\mathrm{t} \mathrm{c} / \mathrm{p} \mathrm{c}$ where, $\mathrm{c} \mathrm{r}$, stands for capacity cost rate, $\mathrm{t} \mathrm{c}$, total cost of the study program, $\mathrm{p} \mathrm{c}$, stands for the total practical capacity of the study program. (Table 6)

Table 6. The practical capacity rate of Academic Programs on College of Administration and Finance

\begin{tabular}{llll}
\hline Study program & Total Costs (1) & Practical Capacity In Minutes(2) & Practical Capacity Rate per Minute(3)=(1/2) \\
\hline Accounting & $\checkmark$ & $\checkmark$ & $\checkmark$ \\
& $\checkmark$ & $\checkmark$ & $\checkmark$ \\
Management & $\checkmark$ & $\checkmark$ & $\checkmark$ \\
E commerce & $\checkmark$ & $\checkmark$ & $\checkmark$ \\
Finance & $\checkmark$ & $\checkmark$ & $\checkmark$ \\
MBA & $\checkmark$ & $\checkmark$ & $\checkmark$ \\
Total & $\checkmark$ & & \\
\hline
\end{tabular}

Source: Prepared By the Researcher.

\subsubsection{Allocating Program Costs to Its Main Activities}

To determine the time needed to perform a single main activity (Kaplan \& Anderson, 2004) suggested using either direct observations or interviews. However, the researcher will use time equations. The nominator, the average time taken to perform a single main activity is estimated by using time equations and characteristics of each main activity. The denominator, Practical Capacity Rate per Minute is available in (Table 6)

Faculty member work is not limited to teaching activities in classes either face to face classes or virtual classes, but also includes other activities such as research; teaching- related activities such as office hours, preparing and marking assignments, preparing and marking exams, exam invigilation, preparing quality files; servicing community; sustaining activities.

Costs of each activity=total estimated time to perform the activity* practical capacity rate (Table 7)

Table 7. Allocating accounting program costs to its main activities

\begin{tabular}{lccc}
\hline Main Activities & Estimated Time In Minutes(1) & Practical Capacity cost rate(2) & $\begin{array}{c}\text { Costs of activities/ Semester } \\
(3)=(1 / 2)\end{array}$ \\
\hline Teaching Activities & $\checkmark$ & $\checkmark$ & $\checkmark$ \\
& & $\checkmark$ & $\checkmark$ \\
Teaching Related Activities & $\checkmark$ & $\checkmark$ & $\checkmark$ \\
Research & $\checkmark$ & $\checkmark$ & $\checkmark$ \\
Community Services & $\checkmark$ & $\checkmark$ & $\checkmark$ \\
Sustaining Activities & $\checkmark$ & $\checkmark$ & $\checkmark$ \\
Total Activities & $\checkmark$ & $\checkmark$ & \\
\hline
\end{tabular}

Source: Prepared By the Researcher. 
(Table 6 and 7) can be repeated for all other academic programs at college of administration and finance.

6.4.5 Unit Cost per Student in Academic Programs

TDABC assumes students consume activities rather than costs. Therefore, unit cost per student for each main activity in each academic program can be calculated by dividing the numerator, costs of each main activity consumed by students over the denominator, no, of students benefiting from this activity. (Table 8)

The cost of unused capacity for each academic program can be calculated by the following equation:

$\mathrm{U} c=(\mathrm{t} t-\mathrm{c} t) \mathrm{c} r$ Where: $\mathrm{u} c$, stands for cost of the unused capacity, $\mathrm{t} t$, stands for total time consumed by all main activities, $\mathrm{c} \mathrm{r}$, stands for practical capacity rate.

The idle capacity in each resource center exists if total time consumed by the main activities is less than the practical capacity supplied in each resource center, in other words the demand for the capacity by the main activities is less than the supplied capacity by the resource center.

Table 8. Unit cost per student in accounting program

\begin{tabular}{llll}
\hline Main Activities & Costs of activities (1) & No. of students (2) & $\begin{array}{l}\text { Cost per student / Semester } \\
(3)=(1 / 2)\end{array}$ \\
\hline Teaching Activities & $\checkmark$ & $\checkmark$ & $\checkmark$ \\
Teaching Related Activities & $\checkmark$ & $\checkmark$ & $\checkmark$ \\
Research & $\checkmark$ & $\checkmark$ & $\checkmark$ \\
Community Services & $\checkmark$ & $\checkmark$ & $\checkmark$ \\
Sustaining Activities & $\checkmark$ & $\checkmark$ & $\checkmark$ \\
Total Activities & $\checkmark$ & $\checkmark$ & $\checkmark$ \\
\hline
\end{tabular}

Source: Prepared by the Researcher.

\section{Conclusion}

The process of allocation of overhead costs is still a chronic problem in cost and managerial accounting for many decades ago. Traditional costing system uses volume based allocation bases such as direct labor hours or machine hours. This system criticized that it miscalculates costs of goods and services due to its assumption that products and services consume costs rather than activities.

In response to the dissatisfaction of the traditional costing system, $\mathrm{ABC}$ has been developed as an alternative to better allocate overhead costs using multiple transaction cost drivers and assuming that products and services consume activities rather than costs. Implementation of $\mathrm{ABC}$ proved that it is expensive, time consuming, subjective and arbitrary process.

In response to the dissatisfaction of $\mathrm{ABC}, \mathrm{TDABC}$ has been developed to overcome the disadvantages of $\mathrm{ABC}$ assuming that time is the main cost driver of overhead costs and focusing of activities within resource centers rather than in separate activity centers as in ABC.TDABC helped in detecting any idle capacity in each resource center. However, TDABC is theoretically appealing; the implementation of it is a challenging process in general and in universities in particular because of many cost objects need to be calculated.

Because of not all previous studies developed a comprehensive and practical framework to implement TDABC in universities, whereas no answers are given to the raised questions by the researcher.

This research proposes a guide to answering the previous questions and implementation of DTABC in SEU.

\section{References}

Barrett, R. (2005). Time-driven costing: the bottom line on the new ABC. Business Performance Management, 35-39.

Berry, R. H. (1994). Management Accounting in Universities. CIMA London.

Broad, M., \& Crowther, D. (2001). Activity Based Costing in Universities - An Inappropriate Technique? The Journal of Applied Accounting Research, 6(2), 55-89.

Byrne, S., \& Tarry. P. (2009). Is ABC Adoption a Success in Australia? Journal of Applied Management Accounting Research, 7(1), 37-52. 
Charafa, K. L., \& Rahmounib, A. F. (2014). Using Importance Performance Analysis to Evaluate the Satisfaction of Activity-Based Costing Adopters. Accounting and Management Information Systems, 13(4), 665-685.

Cooper, P., \& Cook, R. (2000), Activity-Based Costing in Universities Five Years On, Public Money \& Management, $\quad$ April-June 2000, CIPFA. Retrieved from https://www.researchgate.net/deref/http\%3A\%2F\%2Fdx.doi.org\%2F10.1111\%2F1467-9302.00213

Cooper, R. (1987). Does Your Company Need a New Cost System? Journal of Cost Management, 1(1), 45-49.

Cooper, R., \& Kaplan, R. S. (1988). Measure Costs Right: Make the Right Decision. Harvard Business Review, 66(9), 96-103.

Ellis-Newman, J. (2003). Activity-Based Costing in User Services of An Academic Library. Library Trends, $51(3), 333-348$.

Gervais, M., Y. L., \& Ducrocq, C. (2010). Time-Driven Activity Based Costing (TDABC): An Initial Appraisal Through a Longitudinal Case Study. Journal of Applied Management Accounting Research, 8(2), 1-20.

Goddard, A., \& Ooi, K. (1998). Activity-Based Costing and Central Overhead Cost Allocation in Universities: A Case Study. Public Money of Management, 18(3), 31-38.

Hashmi, G. H. (2013). The Activity-based costing (ABC) in a Public Higher Education Institutions (HEI): Stakeholders' perceptions. International Journal of Management \& Information Technology, 7(3), 1125-1135. https://doi.org/10.24297/ijmit.v7i3.699

Hooze, S., \& Hansen, S. (2018). A Comparison of Activity-Based Costing and Time-Driven Activity-Based Costing. Journal of Management Accounting Research, 30(1), 143-167.

Ismail, N. A. (2010). Activity Based Management System Implementation in Higher Education Institutions. Campus Wide Information System, 27, 40-52.

Jurek. P, \& Bras, B. (2012), Activity Based Costing Applied to Automotive Manufacturing. IEEE Power and Energy Society General Meeting, 1-8.

Kaplan, R. S. (1990). The Four-Step Model of Cost System Design. Management Accounting, 71, 22-26.

Kaplan, R. S., \& Anderson, S. R. (2004). Time Driven Activity Based Costing. Harvard Business Review, 82(11), $131-138$

Kaplan, R. S., \& Anderson, S.R. (2007). The Innovation of Time Driven Activity Based Costing. Cost Management, 21(2), 5-15.

Kowsari, F. (2013). Changing in Costing Models from Traditional to Performance Focused Activity Based Costing (PFABC). European Online Journal of Natural and Social Sciences, 2(3).

Langfield-Smih, K. T., \& Hilton, R. W. (2009). Management Accounting: Information for Creating and Managing Value. North Ryde, N.S.W., and MC Graw-Hill.

Lesetedi, E., \& Mohee, R. (2019). Application of Time Driven Activity Based Costing in Botswana Open University. Pan Commonwealth Forum. http://hdl.handle.net/11599/3238

Lutilsky, I. D., \& Dragija, M. (2012). Activity Based Costing as A Means to Full Costing - Possibilities and Constraints for European Universities. Management, 17(1), 33-57.

Massy, W. (2017). Course Level Activity Based Costing as an Academic and Financial Tool. TIAA Institute High Education Series.

Nidoo, M. (2011), Using Activity Based Costing to Manage Private University in South Africa. Problems and Perspectives in Management, 9(4).

Paulo, A., \& Alex, S. (2016). Application of the TDABC Model in the Logistics Process Using Different Capacity Cost Rates. Journal of Industrial Engineering and Management, JIEM, 9(5), 1003-1019.

Pernot, R., \& Van Den, A. (2007). Time-Driven Activity-Based Costing for Inter-Library Services: A Case Study in a University. The Journal of Academic Librarianship, 33(5), 551-560. https://doi.org/10.1016/j.acalib.2007.06.001

Pierce, B., \& Brown, R. (2006). Perceived Success of Costing System. The Journal of Applied Accounting Research, 8, 101-161.

Radringuez-Monory, C., \& Nasiri, A. (2014). Activity Based Costing, Time-Driven Activity Based Costing and Lean Accounting: Differences Among Three Accounting Systems’ Approach to Manufacturing. 
Ratanatunga, J., Tse, S. C., \& Balachandran, K. R. (2012). Cost Management in Srilanka: A Case Study On Volume, Activity and Time as Cost Drivers. The International Journal of Accounting, 47(12), 281-301. https://doi.org/10.1016/j.intacc.2012.07.001

Ringelstein, D. (2018). Time Driven Activity Based Costing: A Critical Review. Journal of New Business Ideas and Trends, 16(3), 20-27.

Santans, A., \& Afonso, P. (2014). Analysis of Studies On Time Driven Activity Based Costing TDABC, The International Journal of Management Science and Information Technology.

Tatikonda, L. U., \& Tatikonda, R. J. (2001). Activity Based Costing for Higher Education Institutions. Management Accounting Quarterly, Institute of Management Accountants.

Varila, M., Seppänen, M., \& Suomala, P. (2007). Detailed cost modelling: a case study in warehouse logistics, International Journal of Physical Distribution \& Logistics Management, 37(3), 184-200. https://doi.org/10.1108/09600030710742416

Weygandt, J. J., Kieso, D. E., \& Kimmel P. D. (2005). Menagerie economics, Accounting, Management and Social Science.

Yulianita, D. S. D., \& Wahuni. (2018). Use of Time Driven Activity Based Costing to Calculate the unit cost per students at faculty of economics of Universities Pendidkan Ganesha. Advance of Economics Business and Management Research, 79(3). https://doi.org/10.2991/teams-18.2019.42

\section{Copyrights}

Copyright for this article is retained by the author(s), with first publication rights granted to the journal.

This is an open-access article distributed under the terms and conditions of the Creative Commons Attribution license (http://creativecommons.org/licenses/by/4.0/). 